ORIGINAL ARTICLE

\title{
Role of Ionomeric Bone Cement in Primary Stapedotomy for Otosclerosis
}

\author{
Mohamed Mostafa ${ }^{1}$, Mohamed Elkahwagi ${ }^{2} \odot$, Ahmed M AbdEl-fattah ${ }^{3}$, Waleed Moneir ${ }^{4}$, Yousef Shabana ${ }^{5}$, Mohamed Ghonim $^{6}$
}

\begin{abstract}
Objective: Crimping of the prosthesis in the primary stapedotomy is a controversial step that can have a great impact on the long-term success of the procedure. The study aims to clarify the role of bone cement in primary stapedotomy with an assessment of the postoperative hearing state. Methods: A prospective randomized clinical study including patients with otosclerosis was conducted. The study population was divided into two equal groups. Group A had primary stapedotomy with crimping of the prosthesis while group B had the procedure with bone cement bridging between the prosthesis and a long process of the incus replacing the crimping step. Data of included patients were collected and included gender, age, family history, and audiological parameters. The outcome measurement was the improved hearing status postoperatively as shown by the 1-month postoperative audiogram. The long-term outcome was the stability of the prosthesis that was measured by the 6-month postoperative audiogram.

Results: Sixty patients were included in the study. A statistically significant improvement of the hearing state was present in both groups in all frequencies $(p<0.05)$. The difference in postoperative air-bone gap at $2000 \mathrm{~Hz}$ between both groups was statistically significant $(p<0.05)$ with better closure in group B. The follow-up period was 1 year postoperatively in all patients.

Conclusion: The use of hydroxyapatite bone cement in primary stapedotomy may have a role in providing stability for the procedure decreasing the incidence of recurrent conductive hearing loss in otosclerosis patients. This can provide a substitute for the problems of malcrimping of the prosthesis.
\end{abstract}

Keywords: Bone cement, Crimping, Long process of incus, Necrosis, Otosclerosis, Revision stapedotomy.

Otorhinolaryngology Clinics: An International Journal (2021): 10.5005/jp-journals-10003-1362

\section{INTRODUCTION}

Otosclerosis is a complex and progressive disease of bone of otic capsule.' Mature lamellar bone is replaced by osteoblasts with the bone of more thickness, cellularity, and vascularity. It mainly affects the stapes footplate especially the fissula ante fenestram and can extend to the inner ear causing cochlear otosclerosis, which can be termed as mixed otosclerosis. ${ }^{3}$

The typical presentation of the disease is the bilateral asymmetrical progressive conductive hearing loss with an intact tympanic membrane. ${ }^{4}$ This presentation is for the stapedial type, which is the commonest. However, mixed hearing loss can occur in cases of cochlear affection that can progress to sensorineural hearing loss. ${ }^{5}$ The hearing loss present in otosclerosis affects the quality of life of the patients greatly with variable degrees according to the degree of hearing loss. ${ }^{6}$

The current management of otosclerosis with conductive hearing loss consists of either hearing amplification via hearing aids or stapes surgery. ${ }^{7}$ The latter had a long history of evolution till reaching the two broad categories: stapedotomy and stapedectomy. ${ }^{8}$ Apart from the compliance problems of the hearing aids use, stapedotomy is a cost-effective option in the treatment. ${ }^{9}$ However, stapes surgery still has some drawbacks, the most important of which is that the probability of needing revision surgery in certain cases, which might affect the patient's decision in the management plan. ${ }^{10}$

Recently, many publications raised the issue of revision stapedotomy with emphasis on the cause of the revision, the surgical findings, and the various techniques for correction. ${ }^{11-13}$ More than $85 \%$ of the causes for the revision included either loose prosthesis, long process of incus (LPI) necrosis, or dislocated

\author{
${ }^{1-6}$ Department of Otorhinolaryngology, Mansoura University, \\ Mansoura, Egypt
}

Corresponding Author: Mohamed Elkahwagi, Department of Otorhinolaryngology, Mansoura University, Mansoura, Egypt, e-mail: dr.mak89.ms@gmail.com

How to cite this article: Mostafa M, Elkahwagi M, AbdEl-fattah AM, et al. Role of Ionomeric Bone Cement in Primary Stapedotomy for Otosclerosis. Int J Otorhinolaryngol Clin 2021;13(1):1-6.

Source of support: Nil

Conflict of interest: None

prosthesis. ${ }^{12,13}$ All these findings are related to a single step in stapes surgery, which is called crimping of the prosthesis. ${ }^{14}$ If this crimping is loose, the risk of dislocation of the prosthesis out of the incus and the loose prosthesis will be present. If this crimping is so tight, the risk of LPI necrosis will be present. ${ }^{10}$

Crimping of the prosthesis over the LPI is a critical step during stapes surgery. Optimal prosthesis fixation is essential for good sound transmission. On the other, the process of manual crimping carries certain risks for middle and inner ear damage. ${ }^{15}$

Bone cement is a substance produced by an acid-base reaction. The formulated powder is mixed with a liquid to generate a mixture that hardens through a reaction. ${ }^{16}$ Bone cement is originally used in dental and craniofacial surgery. ${ }^{17}$ Glass ionomeric cement, which is a type of bone cement, gained the United States Food and Drug Administration approval in 2001 for otological use. ${ }^{11}$ Since then, it has been used in ossiculoplasties and revision stapes surgery. ${ }^{17,18}$

( ) Jaypee Brothers Medical Publishers. 2021 Open Access This article is distributed under the terms of the Creative Commons Attribution 4.0 International License (https://creativecommons.org/licenses/by-nc/4.0/), which permits unrestricted use, distribution, and non-commercial reproduction in any medium, provided you give appropriate credit to the original author(s) and the source, provide a link to the Creative Commons license, and indicate if changes were made. The Creative Commons Public Domain Dedication waiver (http://creativecommons.org/publicdomain/zero/1.0/) applies to the data made available in this article, unless otherwise stated. 
This study aimed to evaluate the role of the hydroxyapatite bone cement in establishing an ideal fixation of the prosthesis over the LPI by using a drop of bone cement to avoid either very tight fixation or loose fixation in crimping during stapes surgery and evaluate the outcome results by using this technique. We hypothesized that using a drop of bone cement to bridge the incus-prosthesis attachment could result in stable connection and better sound transmission. In addition, this could decrease the incidence of recurrent conductive hearing loss after primary stapedotomy.

\section{Methods}

To address the research purposes, the authors designed this prospective clinical study for the management of cases of otosclerosis. Institutional review board approval for prospective evaluation and data collection were obtained before the initiation of the study (reference number R:MS/16.03.76). The study population included patients of stapedial otosclerosis admitted to department of otorhinolaryngology at Mansoura University in the period between December 2017 and December 2018. The patients were divided into two main groups. Group A included 30 patients who had classic microscopic stapedotomy with crimping of the prosthesis over the LPI while group B included 30 patients who had microscopic stapedotomy with bone cement assisted fixation of the prosthesis on the LPI. To be included in the study sample, patients had to fulfill the following inclusion criteria: age between 18 and 60 years, pure stapedial otosclerosis with conductive hearing loss with air-bone gap at least $20 \mathrm{~dB}$ on average at frequencies $0.5,1,2$, and $3 \mathrm{kHz}$ in the speech range, and speech discrimination score of $90 \%$ or better. Exclusion criteria were revision cases, only hearing ear, and air-bone gap less than $20 \mathrm{~dB}$. Data of included patients were collected and included gender, age, family history, and audiological parameters.

\section{Study Variables}

The predictor variable of this study was the method of fixation of the prosthesis on the LPI either by the crimping or the bone cement. The outcome variable was the postoperative hearing improvement determined by the pure-tone audiogram (PTA).

\section{Surgical Approach}

All cases were operated under local anesthesia by using a mixture of $2 \%$ lidocaine in epinephrine 1/50000-1/80000 to reduce bleeding (Fig. 1). Using a round knife, external auditory canal skin was incised from 5 o'clock to 12 o'clock positions on the left side and from 7 o'clock to 12 o'clock positions on the right side approximately 6-8 $\mathrm{mm}$ lateral to the annulus. The incision was then deepened till the exposure of the underlying bone. The tympanomeatal flap was elevated with a round knife toward the annulus (Fig. 2). If the bleeding was encountered, it would have been controlled by cotton soaked with thick epinephrine. When the tympanic annulus was exposed, it was carefully elevated. Detachment of the chorda tympani from its groove was performed gently with its preservation and anterior displacement. Curettage of the part of the posterosuperior bony meatal wall was performed using a curette. Complete evaluation of the ossicles and joints motility was performed to ensure the pathology of stapes fixation. The technique of reverse stapedotomy proposed by House et al. was performed with perforating the oval window and prosthesis insertion prior to the separation of the incudostapedial joint. ${ }^{12}$ This technique prevents transmission of the force of insertion to the oval window. Fenestration of the oval window was performed by a 0.8-mm perforator. Insertion of the prosthesis was performed with very gentle closure (crimping) over the LPI in group A while insertion of a drop of bone cement to bridge the incus-prosthesis junction was performed in group B, and this step was endoscopically documented (Figs 3 and 4). Cutting of the stapedial tendon using a sickle knife and removal of the stapes suprastructure were performed. Reassessment of the sound transmission pathway was achieved by round window reflex. Repositioning of the tympanomeatal flap was performed (Fig. 5). Lastly, packing the external auditory canal using gel foam was performed. Special precautions were taken regarding the use of the bone cement; the cement powder was mixed with its liquid in vitro, and the time for its insertion should not exceed 2 minutes not to harden in vitro, cement powder with its liquid in vitro, gel foam was put around prosthesis covering the oval window and the facial nerve to absorb any drops of bone cement spilled over.

\section{Outcome Measurement}

The early outcome of the study was the improved hearing and closure of the air-bone gap postoperatively measured by the

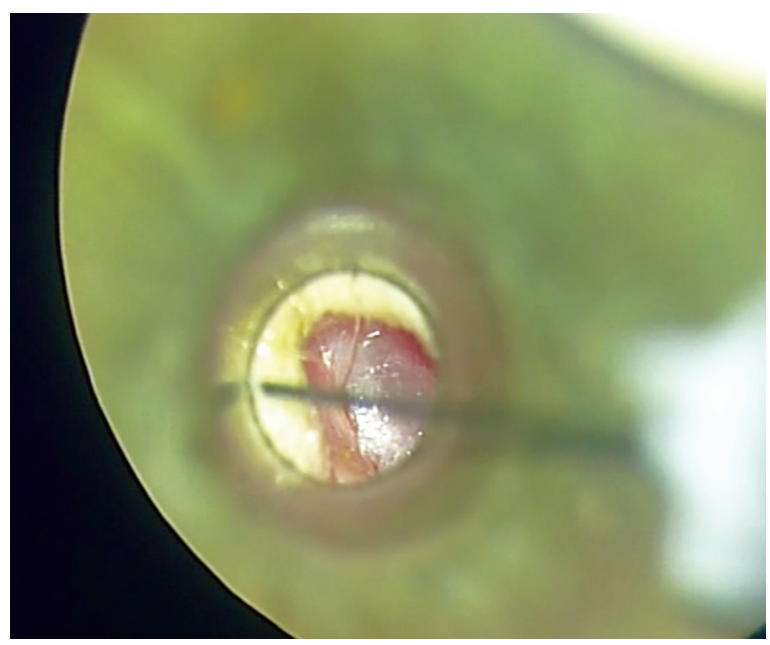

Fig. 1: Injection of local anesthesia

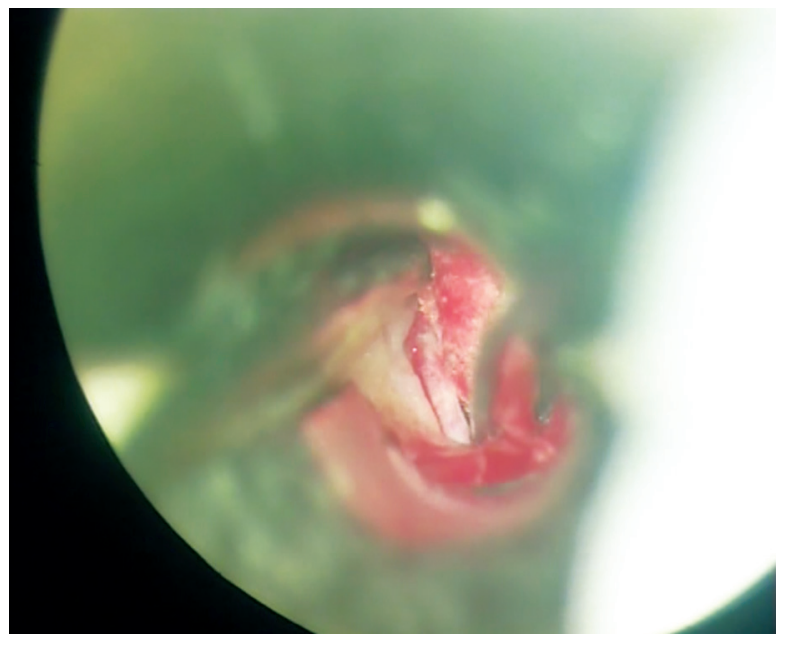

Fig. 2: Elevation of tympanomeatal flap and annulus 


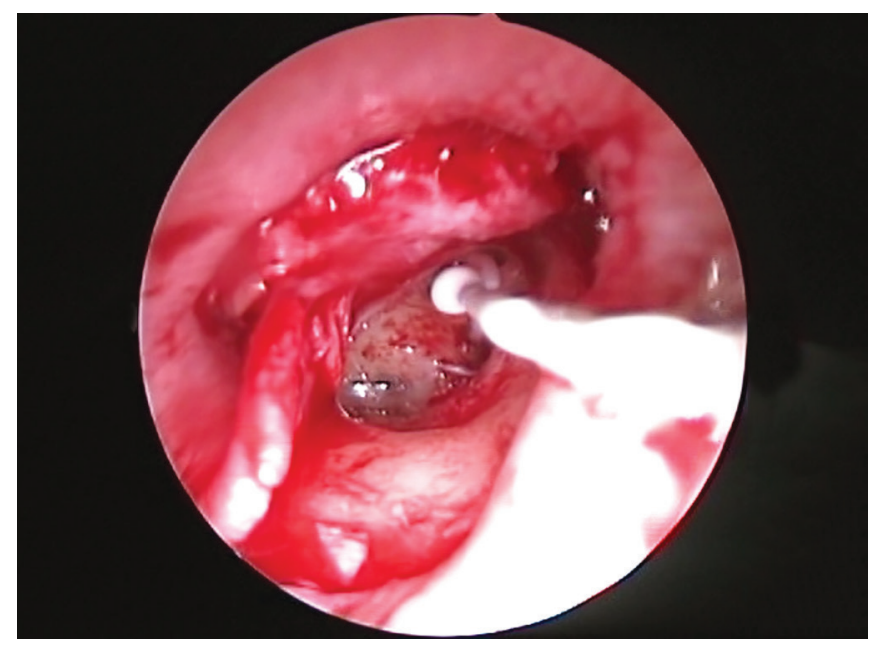

Fig. 3: Insertion of the bone cement point on the incus and the prosthesis

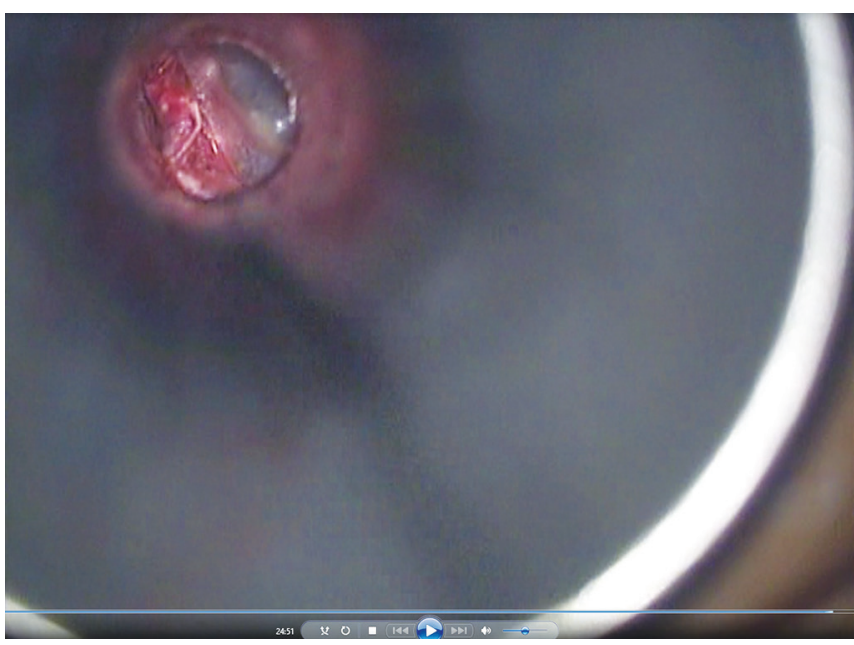

Fig. 5: Repositioning of the intact tympanomeatal flap
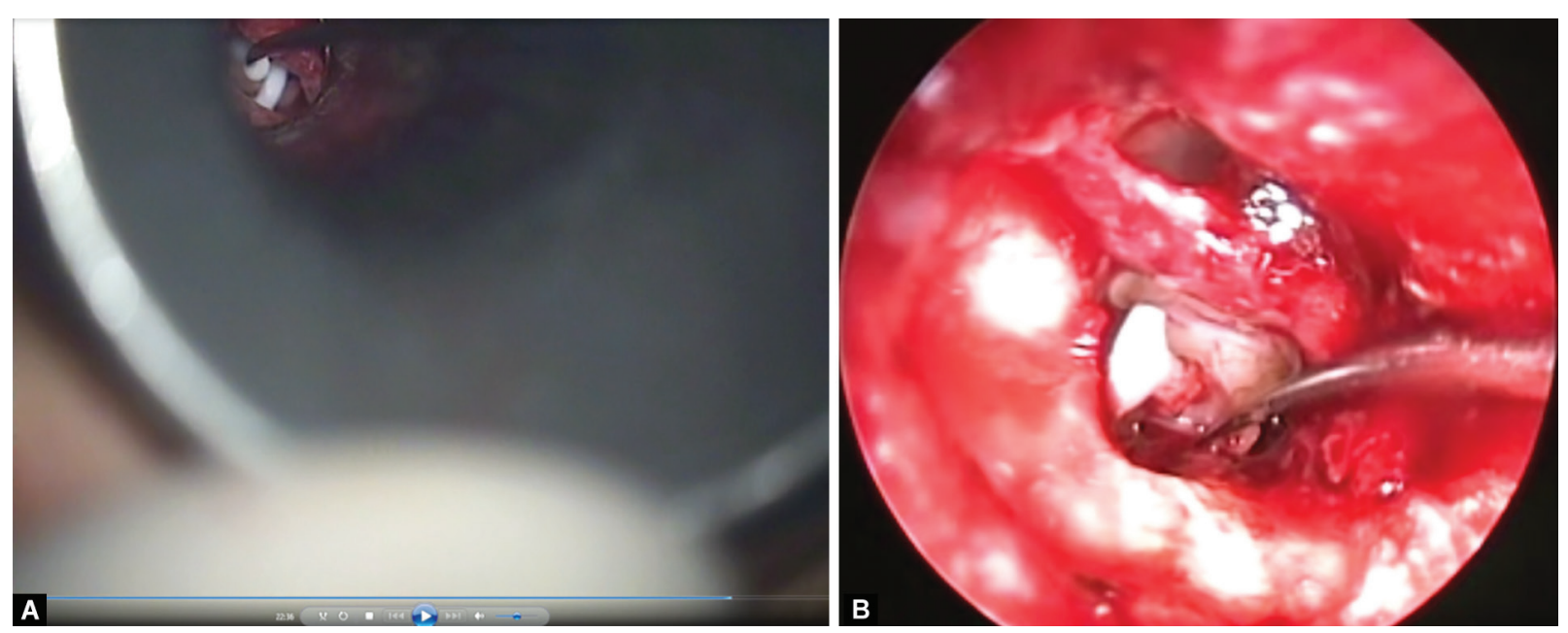

Figs 4A and B: (A) Microscopic view of the bone cement bridging between the incus and the prosthesis; (B) Endoscopic view of the same step

postoperative PTA. The preoperative and postoperative audiograms were performed using a two-channel audiometer. Air conduction was measured via supra-aural headphones, and bone conduction was measured via a bone vibrator. Thresholds were measured at $500,1000,2000$, and $4000 \mathrm{~Hz}$, and the mean \pm \pm standard deviation (SD) air-bone gap was noted. The tests were performed in a locally made sound-treated room. The late outcome was the maintenance of this hearing level, and the absence of the need for revision surgery measured by the follow-up period was 1 year postoperatively.

\section{Statistical Analysis}

Data were analyzed using the Statistical Package for Social Sciences (SPSS) version 15. Qualitative data were presented as number and percent. Quantitative normally distributed data were presented as mean $\pm S D$. Ordinal data and quantitative non-normally distributed data were presented as median and range. Comparison between both groups regarding the hearing state was done by the Student $t$-test. The Chi-square test was used to compare categorical variables between groups. The Mann-Whitney test was used to compare abnormally distributed variables between groups. A two-tailed $p$-value $<0.05$ was considered to be statistically significant.

\section{Results}

The study population included 60 patients divided into two equal groups each included 30 patients. Group A had a classic reverse stapedotomy technique with crimping of the prosthesis on the LPI while group B had the same procedure with bone cement bridging between the prosthesis and the LPI instead of the crimping step. The study included 21 men and 39 women. The mean age of group $A$ was $(32.80 \pm 5.44)$ years while for group $B$ was $(31.0 \pm 7.18)$. Thirty-seven left ears and 23 right ears were operated in the study.

Regarding the hearing improvement after 6 months postoperatively, there were significant statistical differences between the preoperative and postoperative air conduction threshold at $500-4000 \mathrm{~Hz}$ (all $p$-values $<0.05$ ) in both groups. In addition, significant statistical differences between the preoperative and postoperative air-bone gap at $500-4000 \mathrm{~Hz}$ were encountered in both groups (all $p$-values $<0.05$ ). In addition, significant statistical 
Role of Ionomeric Bone Cement in Primary Stapedotomy for Otosclerosis

Table 1: Preoperative and postoperative ( 6 months after surgery) audiometric results (mean \pm standard deviation) for all patients in group $\mathrm{A}$

\begin{tabular}{llcccc}
\hline Frequency in $\mathrm{Hz}$ & & $500 \mathrm{~Hz}$ & $1000 \mathrm{~Hz}$ & $2000 \mathrm{~Hz}$ & $4000 \mathrm{~Hz}$ \\
\hline Air conduction threshold in $\mathrm{dB}$ & Preoperative & $52.0 \pm 11.85$ & $51.0 \pm 13.82$ & $51.25 \pm 12.66$ & $50.50 \pm 11.69$ \\
& Postoperative & $27.0 \pm 7.33$ & $26.50 \pm 8.75$ & $30.75 \pm 9.07$ & $29.25 \pm 7.83$ \\
Bone conduction threshold in $\mathrm{dB}$ & Preoperative & $19.0 \pm 4.47$ & $20.0 \pm 7.07$ & $25.25 \pm 6.97$ & $22.50 \pm 7.69$ \\
& Postoperative & $19.0 \pm 4.47$ & $20.0 \pm 7.07$ & $25.25 \pm 6.97$ & $22.50 \pm 7.69$ \\
& Preoperative & $33.0 \pm 9.09$ & $31.0 \pm 10.34$ & $26.0 \pm 11.65$ & $28.0 \pm 10.31$ \\
Air-bone gap in dB & Postoperative & $8.0 \pm 5.48$ & $6.50 \pm 6.51$ & $5.50 \pm 6.47$ & $6.75 \pm 4.67$ \\
\hline
\end{tabular}

Table 2: Preoperative and postoperative ( 6 months after surgery) audiometric results (mean \pm standard deviation) for all patients in group $B$

\begin{tabular}{llcccc}
\hline Frequency in $\mathrm{Hz}$ & & $500 \mathrm{~Hz}$ & $1000 \mathrm{~Hz}$ & $2000 \mathrm{~Hz}$ & $4000 \mathrm{~Hz}$ \\
\hline Air conduction threshold in dB & Preoperative & $58.50 \pm 9.61$ & $56.25 \pm 10.50$ & $50.75 \pm 14.62$ & $47.75 \pm 17.28$ \\
& Postoperative & $27.25 \pm 15.0$ & $23.50 \pm 8.90$ & $22.75 \pm 8.19$ & $29.25 \pm 12.70$ \\
Bone conduction threshold in dB & Preoperative & $21.50 \pm 9.19$ & $21.50 \pm 8.29$ & $26.50 \pm 8.60$ & $20.75 \pm 9.22$ \\
& Postoperative & $19.0 \pm 6.41$ & $19.0 \pm 6.61$ & $20.25 \pm 8.35(p 0.001)$ & $19.0 \pm 6.81$ \\
Air-bone gap in dB & Preoperative & $37.0 \pm 9.65$ & $34.75 \pm 8.35$ & $24.25 \pm 14.44$ & $27.0 \pm 13.22$ \\
& Postoperative & $8.25 \pm 13.89$ & $4.50 \pm 3.94$ & $2.50 \pm 3.03$ & $5.0 \pm 4.29$ \\
\hline
\end{tabular}

differences between the preoperative and postoperative bone conductive thresholds at $2000 \mathrm{~Hz}$ were present in both groups (all $p$-values <0.05) (Tables 1 and 2).

Postoperative sensorineural hearing loss was defined as a negative value in the bone PTA at three consecutive frequencies exceeding $10 \mathrm{~dB}$. There was a positive value in group $B$ at $2000 \mathrm{~Hz}$, which was statistically significant in comparison with that of group $A$. This notice suggests the better closure of the air-bone gap in group $B$, which was not statistically significant when compared with that of group $A$.

Regarding the complications encountered in this study, two patients (10\%) in group A and three patients (15\%) in group B developed vertigo and vomiting. They were managed by intravenous fluid, corticosteroids, antivertiginous, and antiemetic drugs. All patients improved after 2 days. One patient in group A and 2 in group $B$ had postoperative dysgeusia due to the required cut of the short chorda tympani. This dysgeusia improved on the 6 months follow-up in all patients. In addition, no cases of facial palsy or perforation of the tympanic membrane were recorded.

\section{Discussion}

Stapedotomy is considered the first-line management for cases of otosclerosis as it is a cost-effective safe option for these patients with progressive hearing loss. ${ }^{19}$ However, the need for revision surgery due to recurrent conductive hearing loss is a major drawback of this type of surgery. ${ }^{7,20}$ In the situation of revision surgery for these cases, it has been found that prosthesis displacement and incus necrosis were the most common etiologies of recurring hearing loss. ${ }^{12,21}$ These complications are related to the prosthesis placement over the LPI. ${ }^{4}$ Therefore, in this study, we compared the standard stapedotomy operation done with the crimping of the prosthesis over the LPI with the recent application of the bone cement in the fixation of the prosthesis on the incus.

Hearing loss is the main presenting symptom in otosclerosis patients. Tinnitus is another symptom that is usually present in those patients especially in the active form of the disease. Tinnitus was the second complaint in $50 \%$ of patients. Ertugay et al. revealed the same percentage. ${ }^{22}$ Ayache et al. had reported similar incidences of hearing loss and tinnitus in their patients. ${ }^{23}$ In addition, Nemati et al. documented that $100 \%$ of patients had hearing loss and $51.1 \%$ had tinnitus. ${ }^{24}$ In the current study, hearing loss was the main complaint and was found in $100 \%$ of otosclerotic patients. Tinnitus was present in $80 \%$ of the diagnosed patients.

This study is in line with the proposed use of bone cement in primary stapedotomy made by Goebel and Jacob. ${ }^{17}$ In addition, it is more comprehensive than the study of Rompaey et al. who used the bone cement in the difficult cases of primary stapedotomy and proposed that its use will have a better impact on postoperative hearing as the prosthesis and the incus moves as one unit over the footplate. ${ }^{10}$ Besides, our study agrees with the results of Elzayat et al. study who made a similar comparison like our study between the crimping and bone cement in primary stapedotomy with a larger sample size in our research. ${ }^{14}$

Hydroxyapatite bone cement itself has been shown to be safe and effective in its clinical applications in the middle ear and different forms of ossiculoplasty with minimal reported adverse effects. ${ }^{25}$ It has been shown that bone cement provides many options for hearing reconstruction in cases of LPI necrosis. ${ }^{26,27}$ In this study, we applied the bone cement over the present LPI to fix the prosthesis on it in order to avoid the complication of LPI. In addition, its application offered a more physiological sound transmission as the incus and the prosthesis moved as one unit on palpation. This best explains the good air-bone gap closure in the group of bone cement application up to a mean of $4.5 \mathrm{~dB}$ at $1000 \mathrm{~Hz}$.

The degree of air-bone gap closure is a matter of intensive research in stapes surgery. ${ }^{28}$ Different degrees of gap closure have been reported following stapedotomy. ${ }^{29}$ There is a great consensus that closure of the gap to less than $20 \mathrm{~dB}$ would indicate successful surgery. ${ }^{30}$ In our study, in group A, the mean preoperative air-bone gap was $26.0 \pm 11.65 \mathrm{~dB}$ and the mean postoperative air-bone gap was $5.50 \pm 6.47 \mathrm{~dB}$ at $2000 \mathrm{~Hz}$. In group $B$, the mean preoperative air-bone gap was $24.25 \pm 14.44 \mathrm{~dB}$ and the mean postoperative air-bone gap was $2.50 \pm 3.03 \mathrm{~dB}$ after 6 months at $2000 \mathrm{~Hz}$. The difference in postoperative air-bone gap at $2000 \mathrm{~Hz}$ between both groups was statistically significant $(p<0.05)$. This can be explained by the stable connection between the prosthesis and the LPI made by the bone cement. 
Many studies have discussed the recurrent conductive hearing loss after 1-year stapedotomy. House et al. studied 37 cases of previously treated otosclerosis patients where incus erosion was observed during revision stapedotomy. ${ }^{31}$ Moreover, Rouhani and Lavy managed 27 cases of revision stapedotomy who had incus necrosis using bone cement and had good closure of the air-bone gap. $^{21}$

To solve these issues, different types of stapes prosthesis and different types of adhesive materials were used to secure their attachment to the incus. Singh and Goyal used the titanium soft clip piston to avoid these problems and their results showed good closure of the air-bone gap. ${ }^{32}$ In this study, we used the Teflon piston of $4.5 \mathrm{~mm}$ length and $0.6 \mathrm{~mm}$ diameter of the shaft. This type is commercially available here and is the best in our hands. In addition, hydroxyapatite bone cement was used in group B to bridge the connection between the prosthesis and the LPI to avoid malcrimping complications. No one of our cases presented with recurrent conductive hearing loss during the 1-year follow-up period and no one needed revision of the surgery.

There are some limitations to the study. The relatively small number of cases operated in this study is the first limitation despite being the largest comparative study for the use of bone cement in the primary stapedotomy to the best of our knowledge. Therefore, larger prospective studies are needed to prove the role of bone cement or any other adhesives in stapedotomy. The relatively short follow-up period is another weak point that needs to be investigated by the authors and other authors in the future to investigate the role of bone cement in minimizing the need for revision surgeries for recurrent conductive hearing loss after primary stapedotomy.

\section{ConcLusion}

Necrosis of the LPI and prosthesis displacement are the most common causes for recurrent conductive hearing loss after primary stapedotomy. Therefore, crimping of the prosthesis is an essential step in stapedotomy. However, malcrimping is common and can result in previous complications. The use of hydroxyapatite bone cement to bridge the incus prosthesis attachment can replace the crimping of the prosthesis and result in a stable connection and better sound transmission with minimal complications.

\section{ORCID}

Mohamed Elkahwagi @ https://orcid.org/0000-0002-0404-1534

\section{References}

1. Bianconi L, Gazzini L, Laura E, et al. Endoscopic stapedotomy: safety and audiological results in 150 patients. Eur Arch Oto-Rhino-Laryngol 2020;277(1):85-92. DOI: 10.1007/s00405-019-05688-y.

2. Nazarian R, Shea R. History of otosclerosis and stapes surgery. Otolaryngol Clin North Am 2018;51(2):275-290. DOI: 10.1016/ j.otc.2017.11.003.

3. Yeh C, Wang M, Chu C, et al. Predictors of hearing outcomes after stapes surgery in otosclerosis. Acta Otolaryngol 2019;139(12): 1058-1062. DOI: 10.1080/00016489.2019.1648866.

4. Liu YF, Gupta A, Nguyen SA, et al. Preferences in stapes surgery among American Otological Society otologists. World J Otorhinolaryngol Head Neck Surg 2020;6(1):59-65. DOl: 10.1016/j.wjorl.2019.12.001.

5. Rask-andersen $\mathrm{H}$, Schart-morén $\mathrm{N}$. Special anatomic considerations in otosclerosis surgery. Otolaryngol Clin North Am 2018;51(2):357-374. DOI: 10.1016/j.otc.2017.11.013.
6. Watson GJ. Reporting in stapes surgery: are we following the guidelines? J Laryngol Otol 2018;132(6):479-485. DOI: 10.1017/ S0022215118000397.

7. Wegner I, Verhagen JJ, Stegeman I, et al. A systematic review of the effect of piston diameter in stapes surgery for otosclerosis on hearing results. Laryngoscope 2016;126(1):182-190. DOI: 10.1002/ lary. 25408.

8. Düzenli U, Çatlı T, Gür H, et al. Sixteen years of experience with otosclerosis revision surgery: report of 105 cases. B-ENT 2019;19-24.

9. Gillard DM, Harris JP. Cost-effectiveness of stapedectomy vs hearing aids in the treatment of otosclerosis. JAMA Otolaryngol Head Neck Surg 2019;146(1):1-6. DOI: 10.1001/jamaoto.2019.3221.

10. Rompaey $\vee$ Van, Zarowski A, Vercruysse J, et al. Usefulness of hydroxyapatite bone cement to overcome crimping problems in primary stapedotomy. Otolaryngol Head Neck Surg 2011;7(2):165-171.

11. Chen DA, Arriaga A. Technical refinements and precautions during ionomeric cement reconstruction of incus erosion during revision stapedectomy. Laryngoscope 2003;113(5):848-852. DOI: 10.1097/00005537-200305000-00014.

12. Hudson SK, Gurgel RK, Shelton C. Revision stapedectomy with bone cement : are results comparable to those of standard techniques? Otol Neurotol 2014;35(9):1501-1503. DOI: 10.1097/ MAO.0000000000000580.

13. Lundman L, Strömbäck K, Björsne A, et al. Otosclerosis revision surgery in Sweden: hearing outcome, predictive factors and complications. Eur Arch Oto-Rhino-Laryngol 2020;277(1):19-29. DOI: 10.1007/s00405-019-05652-w.

14. Elzayat ÃS, Younes A, Fouad A, et al. Hearing outcome with the use of glass ionomer cement as an alternative to crimping in stapedotomy. Otol Neurotol 2017;38(9):1240-1245. DOI: 10.1097/ MAO.0000000000001564.

15. Huber AM, Veraguth $D$, Schmid S, et al. Tight stapes prosthesis fixation leads to better functional results in otosclerosis surgery. Otol Neurotol 2008;29(7):893-899. DOI: 10.1097/MAO.0b013e318184f4fo.

16. Ardiç FN, Aykal K, Tümkaya F, et al. Improvement of hearing results by bone cement fixation in endoscopic stapedotomy. J Laryngol Otol 2018;132(6):486-488. DOI: 10.1017/S0022215118000439.

17. Goebel JA, Jacob A. Use of Mimix hydroxyapatite bone cement for difficult ossicular reconstruction. Otolaryngol Head Neck Surg 2005;132(5):727-734. DOI: 10.1016/j.otohns.2005.01.023.

18. Javier I, Domenico F, Cecilia V, et al. Endoscopic revision stapes surgery: surgical findings and outcomes. Eur Arch Oto-RhinoLaryngol 2019;276(3):703-710. DOI: 10.1007/s00405-019-05280-4.

19. Sainz $M$, Valdecasas J, Garófano $M$, et al. Otosclerosis: mid-term results of cochlear implantation. Audiol Neurootol 2007;12(6):401-406. DOI: 10.1159/000106773.

20. Blijleven EE, Wegner I, Tange RA, et al. Revision stapes surgery in a tertiary referral center: surgical and audiometric outcomes. Ann Otol Rhinol Laryngol 2019;128(11):997-1005. DOI: $10.1177 / 0003489419853304$.

21. Rouhani MJ, Lavy J. Revision stapes surgery: a novel technique of overcoming erosion of the long process of incus using hydroxylapatite cement and shape memory piston. Otol Neurotol 2019;40(3):301-304. DOI: 10.1097/MAO.0000000000002150.

22. Ertugay OC, Ata P, Ertugay CK, et al. Association of COL1A1 polymorphism in Turkish patients with otosclerosis. Am J Otolaryngol Neck Med Surg 2013;34(5):403-406. DOI: 10.1016/j.amjoto.2013.02.001.

23. Ayache D, Earally F, Elbaz P. Characteristics and postoperative course of tinnitus in otosclerosis. Otol Neurotol 2003;24(1):48-51. DOI: 10.1097/00129492-200301000-00011.

24. Nemati S, Naghavi E, Kaemnejad E, et al. Middle ear exploration results in suspected otosclerosis cases : are ossicular and footplate area anomalies rare ? Iran J Otorhinolaryngol 2013;25(3):155-159.

25. Wegner I, Berg JWG Van Den, Smit AL, et al. Systematic review of the use of bone cement in ossicular chain reconstruction and revision stapes surgery. Laryngoscope 2014;125(1):1-7. DOI: 10.1002/ lary.24897. 
26. Demir B, Binnetoglu A, Sahin A, et al. Long-term outcomes of ossiculoplasty using bone cement. J Laryngol Otol 2019;133(8): 658-661. DOI: 10.1017/S0022215119001300.

27. Caloway $\mathrm{CL}$, Basonbul RA, Ronner EA, et al. Pediatric endoscopic ossiculoplasty following surgery for chronic ear disease. Laryngoscope 2020;130(12):2896-2899. DOI: 10.1002/lary.28526.

28. Maxwell AK, lii WHS, Gopen QS, et al. Failure to close the gap: concomitant superior canal dehiscence in otosclerosis patients. Laryngoscope 2020;130(4):1023-1027. DOI: 10.1002/lary.28167.

29. Balu R, Kumar M, Govindan P, et al. Small fenestra stapedotomy versus large fenestra stapedectomy in improving hearing ability in patients with otosclerosis: our 10 years experience. Indian J Otolaryngol Head Neck Surg 2019;71(3):304-308. DOI: 10.1007/s12070-019-01710-1.

30. Alessandrini M, Viziano A. Surgical treatment of otosclerosis leading to changes in postural control and quality of life. Laryngoscope 2020;130(10):2448-2454. DOI: 10.1002/lary.28438.

31. House JW, Lupo JE, Goddard JC. Management of incus necrosis in revision stapedectomy using hydroxyapatite bone cement. Otol Neurotol 2014;35(8):1312-1316. DOI: 10.1097/MAO.0000000000000496.

32. Singh P, Goyal A. Our experience with the titanium soft clip piston stapedotomy. Indian J Otolaryngol Head Neck Surg 2013;65(3): 280-282. DOI: 10.1007/s12070-011-0459-4. 